\title{
IMATINIB MESYLATE (STI 571) - A NEW ORAL TARGET THERAPY FOR CHRONIC MYELOGENOUS LEUKEMIA (CML)
}

\author{
Ladislav Chrobák, Jaroslava Voglová \\ Charles University in Prague, Faculty of Medicine and University Hospital in Hradec Králové: $2^{\text {nd }}$ Department of \\ Medicine, Division of Clinical Hematology \\ Summary: The publication provides an up-to-date review of the significance of cytogenetic abnormalities in chronic myelo- \\ genous leukemia (CML) and the development of a promising agent with specific molecular target against tyrosine kinase, \\ product of the BCR-ABL fusion gene, namely imatinib mesylate (STI 571, Glivec). The publication summarizes the \\ achieved results with this compound in the chronic phase CML (in patients resistant to interferon and in newly diagnosed \\ patients) further in patients in the accelerated phase and in blast crisis and in patients in relapse after allogeneic stem cells \\ transplantations for $\mathrm{CML}$. The results in $\mathrm{Ph}+$ acute lymphoblastic leukemia are also presented. The mechanisms of re- \\ sistance to imatinib mesylate and the possibilities how to overcome or circumvent it are mentioned (escalation of the \\ dosage, combination of imatinib with some other treatment modalities as immunotherapy, interferon or convention \\ chemotherapy and development of new drugs).
}

Key words: Chronic myelogenous leukemia; Imatinib mesylate (STI 571, Glivec)

Chronic myelogenous leukemia (CML) is a clonal disorder of hematopoietic stem cells characterized by the Philadelphia (Ph) chromosome (39). Ph chromosome was the first chromosomal abnormality associated with a specific malignant disease in humans, namely CML. Later it was further characterized as a reciprocal translocation between chromosomes 9 and 22 referred to as $\mathrm{t}(9 ; 22)$ (q 34; q 11) (44). The translocation results in the formation of two hybride genes, BCR-ABL on the Ph chromosome and ABLBCR on $9 q^{+}$. The BCR-ABL fusion gene encodes a 210 $\mathrm{kDa}$ cytoplasmic protein ( $\mathrm{p} 210^{\mathrm{BCR}-\mathrm{ABL}}$ ) with elevated tyrosine kinase activity (31) which is regarded as essential to the mechanism that underlies the chronic phase of CML. More than $95 \%$ of patients with CML have a BCR-ABL gene in their leukemia cells. However it is not exclusive to CML because it is found in $10 \%$ to $20 \%$ of adults and in 2 to $5 \%$ of children with acute lymphoblastic leukemia (15, 38). Detection of major BCR-ABL expression at a very low level was also found in blood cells of some healthy individuals (1). BCR-ABL gene has been shown to be a leukemia specific oncoprotein which activates various transduction pathways leading to proliferation, transformation, loss of adhesive properties, decreased apoptosis and genetic instability (14). Since the tyrosine kinase is constitutively active, the cells bypass regulated growth and undergo a malignant transformation (11). The oncogenic character of BCR-ABL was also confirmed by induction of chronic myelogenous leukemia in mice by the Ph 210 bcr/abl gene $(5,29)$. CML encompasses three distinct phases becoming more resistant to treatment in each successive phase. The chronic phase is characterized by expansion of terminally differentiated neutrophils. Within 3 to 5 years the disease progresses to an accelerated phase manifested by increasing constitutional symptoms, progressive splenomegaly, refractorness to standard therapy, rising percentage of blasts without meeting the criteria for acute leukemia. The duration of the accelerated phase may last as long as one year. The terminal acute phase termed blast crisis is characterized by cells that fail to mature and represent undifferentiated myeloid or lymphoid progenitor cells. The BCR-ABL oncogen is present in all stages. The blast crisis is characterized by additional genetic abnormalities (18)

\section{Therapy of CML}

CML can be cured only by hematopoietic stem cell transplantation. Allogeneic bone marrow transplantation is largely limited to younger patients with an HLA-identical sibling in an acceptable health status to tolerate the procedure. Stem cell transplantation should preferably be offered to patients within 1 year of diagnosis. For all other patients chemotherapy was the only therapeutic option. For many years the principal options for treating CML included busulphan and hydroxyurea. Busulphan demonstrated a $90 \%$ hematologic response, but did not alter the progression of the disease. The survival outcome was 3 to 4 years. Hydroxy- 
urea induced to the therapy several years later had a longer duration in chronic phase, but the progression to blast crises was not deterred. The median survival was 4 to 5 years (53). After introduction of interferon $-\alpha($ IFN $-\alpha)$ in the mid 1980 (50) in the therapy of CML the survival compared with hydroxyurea was prolonged. IFN - $\alpha$ induced in $80 \%$ of patients in chronic phase CML a complete hematologic remission and in $26 \%$ patients complete cytogenetic remission (25). The addition of ARA-C to IFN further improved survival but increased toxicity (9).

Novel therapies for CML were pursued and various signal transduction inhibitor were developed, among them STI-571 (imatinib mesylate, Glivec, Gleevec) a 2-phenylaminopyrimidine. Imatinib is a highly selective inhibitor of the protein tyrosine kinase family, which includes BCR$\mathrm{ABL}$ protein, the platelet-derived growth factor (PDGF) receptor and the c-kit receptor $(12,45)$. Imatinib competitively binds to the ATP-binding site of BCR-ABL and inhibits protein tyrosine phosphorylation (47). In vivo studies STI-571 prevented growth of hematopoietic cells that expressed BCR-ABL but did not affect normal cells and their function (11).

\section{Imatinib in the late chronic phase CML}

On the basis of the promising preclinical data, in June 1998 Drucker at al (13) initiated a phase I trial designed to determine the safety and efficiency. The efficiency was found to be with the dose over $300 \mathrm{mg} /$ day. 54 patients in the late chronic phase CML who were unable to tolerate IFN - $\alpha$ or who had no response to the drug were enrolled in the study.

The criteria for response to IFN - $\alpha$ were as follows (49): CHR (complete hematologic response): normalization of peripheral counts and differential count, disappearance of all signs and symptoms of disease

PHR (partial hematologic response): similar to CHR except for persistence of peripheral immature cells (blasts, promyelocytes, myelocytes), persistence but improvement more than $50 \%$ in splenomegaly.

CR (cytogenetic responses)

complete: no evidence of $\mathrm{Ph}$-chromosome positive cells

major: $\mathrm{Ph} 1-35 \%$

minor: $\mathrm{Ph} 36-65 \%$

minimal: $\mathrm{Ph} 66-95 \%$

Out of 54 patients 53 (98\%) achieved CHR and 17 (31\%) major cytogenetic responses. Normal leukocyte and platelet counts were reached usually within four weeks after the initiation of treatment.

Good effect of imatinib therapy was also confirmed in further studies in patients with late chronic phase CML in whom previous therapy with IFN $-\alpha$ failed. In phase II trial a total of 454 patients were treated with $400 \mathrm{mg}$ of oral imatinib daily. Imatinib induced CHR in $95 \%$ of patients, major cytogenetic response in $60 \%$ and $41 \%$ of the total number of patients experienced complete cytogenetic remission. Progression-free survival was $89 \%$ at 18 months (24).

Voglová et al. (54) used the same dose $400 \mathrm{mg}$ of imatinib daily in 34 patients with late chronic phase CML in whom IFN - $\alpha$ failed. Complete hematologic response was achieved in 33 of $34(97 \%)$ patients, complete plus major in $21(63 \%)$ patients. The median follow-up time was 97,5 weeks (23-115). Cytogenetic relapse was observed in 2 of 33 patients $(6 \%)$, additional cytogenetic abnormalities in $4(12 \%)$ patients.

\section{Imatinib as the frontline therapy in CML}

The positive results with imatinib in the late chronic phase CML were followed with the phase III trial in which 1106 patients were randomized to the two arms. Imatinib was used as frontline therapy in 553 patients and the results compared with the same number of patients treated with IFN - $\alpha$ plus ARA-C. Complete cytogenetic remission was achieved in $68 \%$ of patients (vs $7 \%$ in IFN - $\alpha$ plus ARA-C arm). Imatinib was found to have longer time to progression. The results of this study suggest that imatinib should be utilized as frontline therapy in CML (9).

Hematologic responses with imatinib typically occur within 3 months, major cytogenetic responses after 9-12 months of therapy.

The trials with imatinib in late chronic phase or as frontline therapy in CML have shown remarkable results. Imatinib is superior to IFN - $\alpha$ and ARA-C in terms of cytogenetic response, progression rates, tolerability and quality of life. The durability of response, the possible longterm effect and the survival data are unknown. Imatinib is used since June 1998, that means 5 years, the median survival with combination of IFN - $\alpha$ plus hydroxyurea was 89 months (25).It can be only supposed that the survival will be better because of high complete cytogenetic responses as compared with IFN $-\alpha$.

\section{Imatinib in accelerated phase CML}

In accelerated phase CML, phase II trial showed that patients taking $600 \mathrm{mg} / \mathrm{d}$ imatinib had longer time to progression and superior survival when compared to 400 $\mathrm{mg} / \mathrm{d}$. With the two different dosage regimens cytogenetic response with $600 \mathrm{mg} / \mathrm{d}$ was $28 \%$ vs $16 \%$ and survival at 12 months $78 \%$ vs $65 \%$. In 181 evaluated patients the overall hematologic response was $82 \%$ with $34 \%$ CHR. Major cytogenetic response was $24 \%$, complete cytogenetic response $17 \%$. There was no higher toxicity with the $600 \mathrm{mg}$ oral dose (51).

\section{Imatinib in blastic phase CML}

In CML blast crises, two recently published studies showed benefit in using imatinib over standard cytotoxic 
therapies. Seventy-five patients were treated with imatinib in a dose escalation ( $300 \mathrm{mg}$ to $1000 \mathrm{mg}$ ) trial. Fifty-two percent (39 of 75) had a hematologic response and $16 \%$ cytogenetic response. The estimated median overall survival was 6,5 months and the estimated 1 -year survival was $22 \%$. For patients given imatinib mesylate as the frontline therapy for nonlymphoid blast phase disease, the response rate was higher with imatinib mesylate as compared with cytarabine-based chemotherapy ( 7 vs 4 months). Side effects were less severe than those associated with standard chemotherapy (21). In a separate multicenter phase II trial 229 patients in CML blast crises were enrolled, of which 148 (65\%) were newly diagnosed CML and 81 (35\%) had received prior therapy. In $36 \%$ of previously untreated patients a sustained hematological response was noted and $9 \%$ achieved a sustained CHR. Sixteen percent established a major cytogenetic response and $7 \%$ achieved complete cytogenetic response (46).

\section{Imatinib in acute lymphoblastic leukemia Ph+ ALL}

Patients who relapse after intensive combination chemotherapy or allogenic transplantation, or who are refractory to treatment, have few therapeutic options. Ottmann et al. treated with imatinib 56 patients, 48 patients with relapsed or refractory ALL and 8 patients with CML in lymphoid blast crisis (41). Imatinib was given once daily at $400 \mathrm{mg}$ or $600 \mathrm{mg}$. CHR was induced in $29 \%$ of ALL patients and sustained for at least 4 weeks in $6 \%$ of patients. Grade 4 neutropenia $\left(<0,5 \times 10^{9} / 1\right)$ and thrombocytopenia $\left(\left(<10 \times 10^{9} / 1\right)\right.$ occurred in $54 \%$ of patients with ALL. Imatinib therapy resulted in a clinically relevant hematologic response rate in relapsed or refractory $\mathrm{Ph}+\mathrm{ALL}$ patients, but development of resistance and subsequent disease progression were rapid, but the clinically relevant response offers the possibility of SCT.

\section{Imatinib for relapse after allogeneic stem cell transplantation for chronic myelogenous leukemia}

Relapse after allogenic SCT has been treated with donor lymphocyte infusion (DLI), IFN - $\alpha$ therapy, or additional transplantation. Although DLI can produce complete molecular-level response (ie abolishment of the BCR-ABL oncoprotein), it can also cause recurrence of GVHD, myelosuppression-associated complications, and death (30), IFN - $\alpha$ based therapy is only moderately successful, second transplantation is usually reserved for patients whose disease does not responded to DLI.

Imatinib mesylate (400 mg - $1000 \mathrm{mg}$ ) was used in 28 adults with CML that had relapsed after allogenic SCT (22).

Thirteen patients had undergone salvage donor lymphocyte infusion. CHR rate was $74 \%$ (17 of 23 patients) and the cytogenetic response rate was $58 \%$ (15 of 28 patients). The 1 -year estimated survival rate was $74 \%$, complete response in $9(35 \%)$ patients CHR rates were $100 \%$ for chronic phase, $83 \%$ for accelerated phase and $43 \%$ for blastic phase. Recurrence of GVHD occurred in 5 patients (in 3 grade 3 ), severe granulocytopenia in $43 \%$ and thrombocytopenia in $27 \%$. Imatinib effectively controlled CML that recurred after allogenic SCT but was associated with considerable side effects. Imatinib therapy alone may be reasonable especially in patients who still have persistent GVHD at the time of CML recurrence to avoid potential worsening of GVHD (22).

\section{Imatinib mesylate dosage}

Imatinib is used in standard doses of $400 \mathrm{mg} /$ day for patients in chronic phase, $600 \mathrm{mg} /$ day for patients in accelerated phase and up to $1000 \mathrm{mg}$ in blastic transformation. Kantarjian et al. (26) on the basis of positive current clinical experience and the experience with higher doses of imatinib $(600 \mathrm{mg})$ in accelerated phase recommended the investigation of higher dose as frontline therapy in patients with newly diagnosed or in late chronic phase CML to obtain better and more durable complete cytogenetic and possibly molecular remission. Dose adjustment is often necessary due to side effects. When serious hematologic toxicity or non-hematologic adverse effects develop it is usually necessary to stop imatinib and to restart at a lower dose after the toxicity resolved.

\section{Monitoring the response to therapy}

For patients in chronic phase cytogenetic response can occur within 3 months of starting therapy. Marrow assessment with metaphase cytogenetics (flurescence in situ hybridization) can be used after six months for this purpose. Patients in major cytogenetic remission should be optimally monitored by quantitative real-time reverse transcriptase polymerase chain reaction (RT-PCR) for the presence of BCR-ABL transcripts. It is important to continue to perform conventional cytogenetics at regular internal to detect additional chromosomal abnormalities.

\section{Myelosupression}

In the chronic phase the current policy is to interrupt imatinib at the first episode of grade III-IV neutropenia/or thrombocytopenia. Treatment can be resumed once the absolute neutrophil count has risen above $1 \times 10^{9} / 1$ and/or the platelet count above $100 \times 10^{9}$. If the blood counts fails to recover within two weeks, it is recommended to reintroduce imatinib at the lower dosage of $300 \mathrm{mg}$ (36).

In patients in blastic phase the support with red cells, platelet transfusions and G-CSF is usually necessary.

\section{The non-hematologic side effects $(36,54)$}

Increase of weight and peripheral edema occur in about $60 \%$ of patients. Common are muscle craps, bone pain and 
arthralgias. Normally the patients respond well to non steroidal anti-inflammatory drugs. Relatively common are skin rashes. They usually appear soon after commencing imatinib therapy, but may developed several weeks or even months later. Hsiao et al. reported a patient in blast crisis who developed a lifethreatening cutaneous reaction, Stevens-Johnson syndrome, following 1 week of mesylate therapy (20). Hepatotoxicity grade II - IV has been reported in $2-15 \%(36,54)$. It typically presents as mild hepatitis, but a cholestatic pattern has been also seen. Other less frequent non-hematologic side effects include fatigue, weakness, dyspepsia, pyrexia, anorexia, hypokaliemia. Increase of intraocular pressure was also noticed in one patient (54).

\section{Resistance of CML to imatinib mesylate}

Imatinib demonstrated remarkable activity in CML but a critical clinical problem is the resistance to this compound. The estimated 2 year incidence of imatinib resistance was $10 \%$ in the chronic phase and $40 \%$ to $50 \%$ in accelerated phase post interferon - $\alpha$ failure (26).

The relative resistance of blast phase to imatinib was considered to be consistent with the hypothesis that secondary mutations (and not BCR-ABL itself) are responsible for the resistance. Nevertheless Deininger et al. (6) made the observation that some cells do escape to the pro-apoptotic effect of mesylate and are able to establish a subline of cells that can grow continuously in the presence of pharmacologic concentrations of imatinib that inhibit growth of most other CML lines. It has been also observed that some quiescent $\mathrm{CD} 34+\mathrm{Ph}+$ cells were highly insensitive to imatinib (19). A variety of mechanisms involved in imatinib resistance to CML have been described $(17,32)$. They include BCR-ABL amplifications (an extra Ph chromosome or high level of BCR-ABL mRNA for other reasons) (55), or mutations within the protein kinase domain (3). Up till now at least 9 different point mutations have been identified (33). There is currently little insight into the underlying mechanism that leads to BCR-ABL gene amplification or mutation. It has been suggested that BCR-ABL itself may confer a mutator phenotype leading to greater genetic instability during disease progression. Some data lead one to believe, that clinical resistance to imatinib, just like antibiotic resistance to bacteria, arises through a process by which pre-existing mutant cells outgrow drug sensitive cells (34). It has been recently confirmed that BCR-ABL mutations preexist in patients who had never received imatinib (16). Further mechanisms of resistance are increased levels of plasma $\alpha-1$ acid glycoprotein (16), that binds to imatinib in the serum and blocks its activity against BCR-ABL, overexpression of Pgp multidrug resistant protein, that may impair the uptake of imatinib by resistant subline (35), some other tyrosine kinases (7), enhanced expression of the interleukin 3 which protects BCR-ABL transformed hematopoietic progenitor cells from apoptosis induced by BCR-ABL tyrosine kinase inhibitors (10).
A critical clinical question is how to overcome or circumvent the resistance. The escalation of the dosage is successful in some cases but not in other $(4,26)$. It has been observed, that patients who have become resistant to the drug responded again if imatinib has been temporarily interrupted (52). Most promising approach is the combination of imatinib with other treatment modalities such as immunotherapy with specific vaccines (42), interferon, convention chemotherapy (ARA-C) (37) which are now being examined. Other possibilities are to combine various signal transduction pathway inhibitors $(8,48)$. One might exploit drugs that trigger BCR-ABL protein degradation such as geldamycin or 17-AGG (2). A number of novel agent are still under investigation for treatment of CML. Homoharringtonine, a plant alkaloid (27, 40), decitabine, a potent hypomethylating agent (23), fernesyltransferase inhibitor (28) and other have shown activity in CML.

\section{References}

1. Biernaux C, Loos M, Sels A et al. Detection of major bcr-abl expression at a very low level in blood cells of some healthy individuals. Blood 1995; 86:118-22.

2. Blagosklonny MV, Fojo T, Bhalla KN et al. The Hsp 90 inhibitor geldamycin selectively sensitizes Bcr-Abl-expressing leukemia cells to cytotoxic chemotherapy. Leukemia 2001;15:1537-43.

3. Branford S, Rudzki Z, Walsh S et al. High frequency of point mutations clustered within the adenosine tri-phosphate-binding region of BCR/ABL in patients with chronic myeloid leukemia or Ph-positive acute lymphoblastic leukemia who developed imatinib (STI 571) resistance. Blood 2002;99:3472-5.

4. Cortes JE, Talpaz M, Giles F et al. High-dose imatinib mesylate (STI 571, Gleevec) in patients with chronic myeloid leukemia (CML) resistant or intolerant to interferon-alpha (IFN) induces molecular remission. Blood 2002;100:Abstr. 616

5. Dalay GQ, Van Etten RA, Baltimore D. Induction of chronic myelogenous leukemia in mice by the $\mathrm{Ph} 210 \mathrm{bcr} / \mathrm{abl}$ gene of the Philadelphia chromosome Science 1990;247:824-30.

6. Deininger MW, Goldman JM, Lydon N et al. The tyrosine kinase inhibitor CGP 57148B selectively inhibits the growth of BCR-ABL positive cells. Blood 1997;90:3691-8

7. Donato NJ, Wu JY, Stapley J et al. BCR-ABL independence and LYN kinase overexpression in chronic myelogenous leukemia cells selected for resistance to STI 571. Blood 2003;101:690-8.

8. Donato NJ, WU JY, Talpaz M. Novel tyrosine kinase inhibitors suppress BCRABL signaling and induce apoptosis in STI 571 sensitive and resistant CML cells. Blood 2002:100:Abstr. 1434

9. Drucker BJ. for IRIS (International Randomized INF vs STI-571 (Gleevec, Glivec, imatinib) versus interferon (INF) + cytarabin as initial therapy for patients with CML: results of randomized study. Proc Am Soc Clin Oncol 2002; 21:1a (Abstract).

10. Dorsey JF, Cunnick JM, Lanchart R et al. Interleukin-3 protects Bcr-Abl-transformed hematopoietic progenitor cells from apoptosis induced by Bcr-Abl tyrosine kinase inhibitors. Leukemia 2002;16:1589-95.

11. Drucker BJ, Lydon NB. Lessons learned from the development of an abl tyrosine kinase inhibitor for chronic myelogenous leukemia. J Clin Invest 2000;105:3-7.

12. Drucker BJ, Sawyers CL, Katarjian H. Activity of a specific inhibitor of the BCR$\mathrm{ABL}$ tyrosine kinase in the blast crises of chronic myeloid leukemia and acute lymphoblastic leukemia with the Philadelphia Chromosome. N Engl J Med 2001;344:1038-42.

13. Drucker BJ, Talpaz M, Resta DJ et al. Efficacy and safety of a specific inhibitor of the BCR-ABL tyrosine kinase in chronic myeloid leukemia. N Engl J Med 2001;344:1031-7.

14. Drucker BJ, Tamura S, Buchdunger E et al. Effect of a selective inhibitor of the abl tyrosine kinase on the growth of BCR-ABL positive cells. Nature Medicine 1996;2:561-6.

15. Faderl S, Talpaz M, Estrov $\mathrm{Z}$ et al. The biology of chronic myeloid leukemia. N Engl J Med 1999;341:164-72.

16. Bambacorti-Passerini $\mathrm{C}$, Barni $\mathrm{R}$, le Contre $\mathrm{P}$ et al. Role of alpha-1 acid glycoprotein in the in-vivo resistance of human Bcr-Abl+ leukemic cells to the Abl inhibitor STI 571. J Natl Cancer Inst 2000;92:1641-50.

17. Gorre ME, Mohamed M, Elwood K et al. Clinical resistance to STI-571 cancer therapy caused by BCR-ABL gene mutation and amplification. Science 2001; 293:876-80. 
18. Gorre ME, Sawyers CHL. Molecular mechanisms of resistance to STI 571 in chronic myeloid leukemia. Current Opin Hematol 2002;9:303-7.

19. Graham S, Jörgensen H, Allan E et al. A significant proportion of CD 34+ progenitor cells survive exposure to STI 571 independent of their position in cell cycle. Blood 2001;96:Abstr. 1482

20. Hsiao LT, Chung HM, Lin JY et al. Steven-Johnson syndrome after treatment with STI 571: a case report. Br J Haematol 2002;117:620-2.

21. Kantarjian HM, Cortes J, O'Brien S. Imatinib mesylate (STI 571) therapy for Philadelphia chromosome-positive chronic myelogenous leukemia in blast phase. Blood 2002;99:3547-53.

22. Kantarjian HM, O'Brien S. Cortes JE et al. Imatinib-mesylate therapy for relapse after allogeneic stem cell transplantation for chronic myelogenous leukemia. Blood 2002;100:1590-5.

23. Kantarjian HM, O'Brien SM, Keating M et al. Results of decitabine therapy in accelerated and blastic phases of chronic myelogenous leukemia. Leukemia 1997;11:1617-20.

24. Kantarjian H, Sawyers C, Hochhaus A et al. Hematologic and cytogenetic responses to imatinib mesylate in chronic myelogenous leukemia. $\mathrm{N}$ Engl $\mathrm{J}$ Mec 2002;246:645-52.

25. Kantarjian HM, Smith TL, O'Brien SM et al. Prolonged survival in chronic myelogenous leukemia after cytogenetic response to interferon - alpha therapy. Ann Intern Med 1995;122:254-61.

26. Kantarjian HM, Talpaz M, O'Brien S et al. Dose escalation of imatinib mesylate can overcome resistance to standard dose therapy in patients with chronic myelogenous leukemia. Blood 2003;101:473-5.

27. Kantarjian HM, Talpaz M, Santini V et al. Homoharringtonine history, current research, and future directions. Cancer 2001;92:1591-1604.

28. Keating A. Chronic myeloid leukemia: current therapies and the potential role of farnesyl-transferase inhibitors. Semin Hematol 2002;39(suppl.2):11-7.

29. Kelliher M, McLaughlin, Witte $\mathrm{O}$ et al. Induction of a chronic myelogenous leukemia - like syndrome in mice with V-abl and bcr/abl. Proc Natl Acad Sci USA 1990;87:6659-63.

30. Kolb HJ, Schattenberg A, Goldman JM et al. Graft-versus-leukemia effect of donor lymphocyte transfusions in marrow grafted patients. Blood 1995;86:2041-50.

31. Konopka JB, Watanabe SM, Singer JW et al. Cell lines and clinical isolates derived from $\mathrm{Ph} 21$-positive chronic myelogenous leukemia patients express $\mathrm{C}$-ab proteins with a common structural alteration. Proc Natl Acad Sci USA 1985; 82:1810-14

32. Le Coutre P, Tassi E, Varella-Garcia M et al. Induction of resistance to Abelson inihibitor STI 571 in leukemic cells through gene amplification. Blood 2000; 95:1758-66.

33. Luzzatto L, Frassoni F, Melo JV. Imatinib: can one outwit chronic myeloid leukemia? Haematologica 2002;87:898-900.

34. Luzzato L, Melo JV. Acquired resistance to imatinib mesylate: selection for preexisting mutant cells. Blood 2002;100:1105.

35. Mahon FX, Deininger MWN, Schultheis B et al. Selection and characterization of BCR-ABL positive cell lines with differential sensitivity to tyrosine kinase in hibitor STI 571: diverse mechanism of resistance. Blood 2000;96:1070-9.

36. Marin D, Marktel S, Bua M et al. The use of imatinib (STI 571) in chronic myeloid leukemia: some practical considerations. Haematologica 2002;87:979-86.

37. Mauro MJ, O'Dwyer ME, Stone RM et al. Preliminary evaluation of the combination of imatinib mesylate (Gleevec) with low dose Ara-C as initial therapy for newly diagnosed chronic phase CML. Blood 2002;100:Abstr. 617.

38. Melo JV. The diversity of BCR-ABL fusion proteins and their relationship to leukemia phenotype. Blood 1996;88:2375-84.

39. Nowell PC, Hungerford DA. A minute chromosome in human chronic granulocytic leukemia. Science 1960;32:1497.
40. 0'Briens S, Kantarijan H, Keating M et al. Homoharringtonine therapy induces responses in patients with chronic myelogenous leukemia in late chronic phase. Blood 1995;86:3322-6.

41. Ottmann OG, Drucker BJ, Sawyers CHL et al. A phase 2 study of imatinib in patients with relapse or refractory Philadelphia chromosome-positive lymphoid leukemias. Hematol J 2002;3:2-6.

42. Pinilla - Ibarz J, Cathcart K, Korontsvit T et al. Vaccination of patients with chronic myelogenous leukemia with bcr-abl oncogene breakpoint fusion peptides generates specific immune responses. Blood 2000;95:1781-7.

43. Roche-Lestienne C, Soenen-Cornu V, Grardel-Duffos $\mathrm{N}$ et al. Several types of mutations of the Abl gene can be found in chronic myeloid leukemia patients resistant to STI 571, and they can pre-exist to the onset of treatment. Blood 2002; 100:1014-8.

44. Rowley JD. A new consistent abnormality in chronic myelogenous leukemia identified by quinacrine fluorescence and Giemsa staining. Nature 1973:243:290-3.

45. Savage DG, Antman KH. Imatinib mesylate - a new oral target therapy. N Engl J Med 2002;346:683-93

46. Sawyers CL, Hochhaus A, Feldman E et al. Imatinib induces hematologic and cytogenetic responses in patients with chronic myelogenous leukemia in myeloid blast crises: results of a phase II study. Blood 2002;99:3530-9.

47. Shindler T, Bornmann W, Pellicena P et al. Structural mechanisms for STI 571 inhibition of abelson tyrosine kinase. Science 2000;289:1938-42.

48. Sun X, Layton JE, Elefanty A et al. Comparison of effects of the tyrosine kinase inhibitors AG 957, AG 490, and STI 571 on BCR-ABL - expressing cells, demonstrating synergy between AG 490 and STI 571. Blood 2001;97:2008-15.

49. Talpaz M, Kantarjian HM, Mc Credie K et al. Interferon - Alpha produces sustained cytogenetic responses in chronic myelogenous leukemia. Ann Intern Med 1991;114:532-8.

50. Talpaz M, McCredie KB, Mavligit GM et al. Leukocyte interferon-induced myeloid cytoreduction in myelogenous leukemia. Blood 1983:62:689-92.

51. Talpaz M, Silver RT, Drucker BJ. Imatinib induces durable hematologic and cytogenetic responses in patients with accelerated phase chronic myeloid leukemia: results of a phase 2 study. Blood 2002;99:1928-37

52. Tipping AJ, Mahon FX, Lagarde V et al. Restoration of sensitivity to STI 571 resistant chronic myeloid leukemia cells. Blood 2001;98:3864-7.

53. Tsao AS, Kantarjian H, Talpaz M. STI 571 in chronic myelogenous leukemia. $\mathrm{Br}$ J Haematol 2002;119:15-24.

54. Voglová J, Poznarová A, Chrobák L et al. Imatinib mesylát (Glivec) v léčbě chronické myeloidní leukemie. Vnitř Lék 2003;43 (in press).

55. Weisberg E, Griffin JD. Mechanism of resistance to the ABL tyrosine kinase inhibitor STI 571 in BCR/ABL - transformed hematopoietic cell lines. Blood 2000;95:3498-505.

Submitted April 2003.

Accepted May 2003.

Prof. MUDr. Ladislav Chrobák, CSc.,

University Hospital in Hradec Králové,

$2^{\text {nd }}$ Department of Medicine,

Division of Hematology,

Sokolská 581, 50005 Hradec Králové,

Czech Republic.

e-mail: ladislavchrobak@seznam.cz 